\title{
露 revistainvi
}

\section{Dossier}

Volumen 36, mro. 101, mayo 2021 ISSN $0718-1299$

- 8 hy

L9y-1959



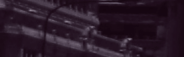

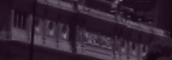

arise

\section{Corredores urbanos:} varifiah centralidades - Iongitudinales de articulaciónglobal

Recibido: 2021-02-22

Aceptado: 2021-07-28

Cómo citar este artículo:

Carrión Mena, F. y Cepeda Pico, P. (2021). Corredores urbanos: centralidades longitudinales de articulación global. Revista INVI, 36(102),183-207.https://doi.org/10.4067/S0718$\underline{83582021000200183}$

Investigación original iniciada en 2020, fundamentada en la propuesta del Corredor Metropolitano de Quito.

\section{Fernando Carrión Mena}

Facultad Latinoamericana de Ciencias Sociales, FLACSO, Ecuador, fcarrion@flacso.edu.ec https://orcid.org/0000-0002-7721-9241

\section{Paulina Cepeda Pico}

Facultad Latinoamericana de Ciencias Sociales, FLACSO, Ecuador, pccepedafl@flacso.edu.ec

https://orcid.org/0000-0002-1914-8107 


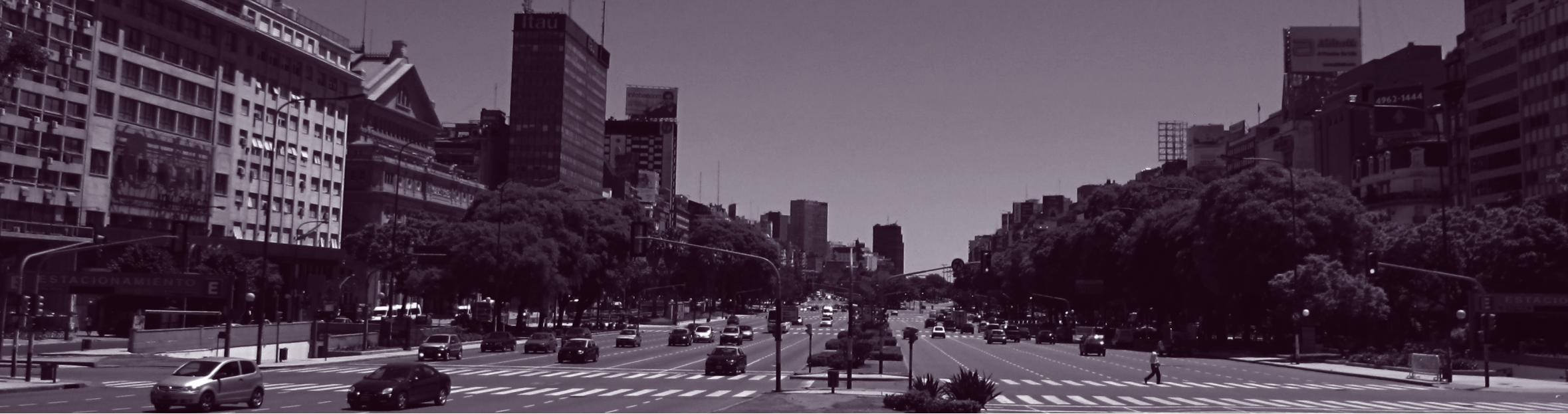

\section{Corredores urbanos: centralidades longitudinales de articulación global}

Palabras clave: desarrollo urbano; corredor urbano; globalización.

\section{Resumen}

Las nuevas formas de acumulación global producen transformaciones constantes y aceleradas de las urbes, no solo en las escalas de análisis, sino también en los paradigmas de planificación. Este artículo aborda la configuración de los nodos de articulación global de América Latina identificados como corredores urbanos o centralidades longitudinales, que configuran una relación lugar-flujo de las actividades intraurbanas y transurbanas. Con el fin de determinar su transformación de avenidas principales a centralidades globales, se analizan los casos de corredores urbanos más importantes mediante una metodología comparativa y en función de cuatro factores: históricos, de funcionalidad, de accesibilidad y de territorialidad. A partir de ello se verifica la transformación de las avenidas urbanas en corredores globales y, sobre todo, en nuevas centralidades. 


\section{*.*vis revistainvi}

\section{Introducción}

La ciudad contemporánea debe ser entendida como un palimpsesto que resulta de múltiples transformaciones; la más reciente es la de una ciudad nuclear -desplegada en un territorio y en un Estado-nación- que se convierte en una región urbana inscrita en un sistema urbano global multiescalar, relacionado más a los patrones de acción de las grandes corporaciones económicas privadas que a las políticas estatales (Castells, 1997).

Las inéditas formas de acumulación del capital, propias del proceso de globalización, transforman la estructura de las ciudades, conduciendo a que la centralidad urbana modifique sus espacios tradicionales para dar lugar a la forma longitudinal actual. Esta inédita centralidad, a la manera de un corredor urbano, se comporta como eje configurador de regiones urbanas y de integración al sistema transurbano global. Para que ello ocurra, su original configuración de avenida (autopista, vía de tren, camino) destinada al flujo de personas, bienes y servicios, muta a la condición de nodo articulador multiescalar (centralidad) del barrio, la zona, la ciudad y la región urbana, en contextos inter y transurbanos globales ${ }^{1}$.

Con este artículo se busca mostrar cómo aquellos filamentos articuladores de regiones urbanas se convierten en factores determinantes en la conformación de las redes urbanas globales. Para ello, se realizará un análisis comparativo de varios corredores paradigmáticos de América Latina, cada uno de los cuales tiene que ver con la jerarquía de la ciudad y su incidencia global (Rojas et al., 2005; "The world according to GaWC", 2020).

Se busca responder a la interrogante: ¿Cómo se transforman los ejes de movilidad intraurbana en centralidades longitudinales de articulación transurbana global? La respuesta hipotética sigue la línea de que los procesos de globalización y las nuevas condiciones del sistema de acumulación capitalista establecen inéditas formas de centralidad urbana, como los denominados corredores urbanos o centralidades longitudinales, que sufren fuertes cambios en su conformación, concentrando actualmente al terciario superior de la economía como función central y mutando desde ser vías de alto tránsito de bienes, personas, información a centralidad urbana.

El contenido del trabajo se desarrolla en tres secciones articuladas entre sí. La primera, la metodología, que abarca la selección de casos, el estudio comparativo y la estructuración de variables. La segunda, el abordaje teórico de las condiciones de reestructuración de las centralidades urbanas y su relación con los procesos de acumulación de capital. La tercera, analiza la operatoria de los corredores urbanos en América Latina, para lo cual se ha seguido una metodología inductiva, es decir, del análisis de los casos más sobresalientes. Y la cuarta, donde se presentan algunas reflexiones finales a manera de conclusiones.

1 En el DRAE, el término "interurbano" significa comunicación y relación entre ciudades o poblaciones, y "transurbano", que no existe en el DRAE, establece la nueva forma de relación entre y a través de las ciudades. 


\section{粼 revistainvi}

\section{Metodología}

En todas las grandes ciudades existen arterias, avenidas, calles, vías, carreteras y rutas que han tenido un peso gravitante en las estructuras urbanas según el momento histórico y el tipo de ciudad que se trate. Para comprender este proceso, se asumen metodológicamente tres consideraciones clave para el presente trabajo: i) determinación de casos de ciudades y corredores; ii) visión histórica para captar el tránsito de la función integradora de los espacios intraurbanos a la de filamentos longitudinales que articulan el sistema transurbano global $^{2}$; y iii) estructuración de una entrada analítica a partir de los componentes que definen la centralidad urbana.

En cuanto al primer punto, se utilizan dos criterios fundamentales de selección de casos para el análisis: i) ciudades latinoamericanas de mayor desarrollo identificadas jerárquicamente según rankings; y ii) corredores intraurbanos, configurados y estructurados como nodos de interacción dentro de las ciudades, que son las principales vías de conexión de las urbes y del sistema urbano global.

Las ciudades seleccionadas de América Latina corresponden a las de mayor primacía urbana y desarrollo económico ${ }^{3}$ dentro de sus países y de la región. Pero también responden a la tipología desarrollada por Cuadrado-Roura \& Fernández (2005) y por la Globalization and World Cities Research Network (GaWC) de inserción diferenciada a la globalización. Para dicha tipología, se parte de una segmentación de siete tipos de áreas metropolitanas mundiales, entre las que las latinoamericanas aparecen en el tercer nivel, como se puede apreciar en la Tabla 1. Adicionalmente, se debe destacar la diversidad de población concentrada que existe, por ejemplo, entre el área metropolitana de São Paulo y de Ciudad de México, que son grandes, y Montevideo y La Paz, más bien pequeñas; como, también, que São Paulo es la única ciudad que no es capital nacional.

La ciudad nuclear, que combina concentración y dispersión espacial, da lugar a nuevas dinámicas territoriales inscritas en una región urbana multiescalar, en la que intervienen jurisdicciones de distinto nivel: global, nacional, intermedio y local ${ }^{4}$. En este contexto, los corredores urbanos operan como un espacio de integración de la región urbana y del sistema transurbano global, desde el territorio intraurbano.

2 Secchi (2001) manifiesta: "A diferencia de lo que habitualmente se piensa: [...] las grandes estructuras comerciales no se desarrollan con grandes centros comerciales [...] sino que se desarrollan con la formación de larguísimas carreteras-mercado". Sobre las carreteras se localizan grandes espacios de venta y urbanización continua a modo de filamento, lo que da lugar a un modo de habitar diferente.

3 La región de São Paulo representa casi el 60\% de la economía de Brasil, mientras que el Gran Santiago constituye el 47 \% del PIB de Chile.

4 Área Metropolitana de México, 5 estados y 173 municipios; Buenos Aires, 2 provincias y 43 partidos; Lima, 2 provincias y 50 municipios; Santiago, 6 provincias y 52 comunas, entre otros. 


\section{Tabla 1.}

Categorización de corredores urbanos según jerarquía de ciudades.

\begin{tabular}{|c|c|c|c|c|}
\hline Jerarquía ciudad (GaWC / IDB) & Ciudad & $\begin{array}{l}\text { Población Región } \\
\text { Metropolitana (2020) }\end{array}$ & Corredor Urbano (CU) & $\begin{array}{l}\text { Extensión CU } \\
(\mathrm{km})\end{array}$ \\
\hline $\begin{array}{l}\text { 1. Metrópolis globales } \\
\text { consolidadas }\end{array}$ & Nueva York & 22100000 & Quinta Avenida & 10.0 \\
\hline \multirow{2}{*}{ 2. Metrópolis globales emergentes } & París & 11400000 & Campos Eliseos & 2.0 \\
\hline & Tokio & 40400000 & Calle Chuo-Dori Ginza & 4.0 \\
\hline \multirow{3}{*}{ 3. Metrópolis continental avanzada } & São Paulo & 22400000 & Avenida Paulista & 3.0 \\
\hline & CD México & 23000000 & Paseo de la Reforma & 14.7 \\
\hline & Buenos Aires & 17540000 & Avenida Corrientes & 8.6 \\
\hline \multirow{3}{*}{$\begin{array}{l}\text { 4. Metrópolis continental en proceso } \\
\text { de desarrollo }\end{array}$} & Santiago de Chile & 8125000 & $\begin{array}{l}\text { Alameda General Bernardo } \\
\text { O'Higgins }\end{array}$ & 7.7 \\
\hline & Bogotá & 10700000 & Carrera Séptima & 24.0 \\
\hline & Caracas & 3750000 & Avenida Libertador & 6.0 \\
\hline \multirow{3}{*}{ 5. Metrópolis nacionales avanzadas } & Montevideo & 1940000 & Ramblas de Montevideo & 24.0 \\
\hline & Lima & 10775000 & Paseo de la República & \\
\hline & Quito & 2780000 & Avenida Guayaquil & 43.8 \\
\hline \multirow{2}{*}{$\begin{array}{l}\text { 6. Metrópolis nacionales bajo } \\
\text { desarrollo }\end{array}$} & La Paz & 2927000 & Paseo del Prado & 13.0 \\
\hline & Brasilia & 4600000 & Gran Eje Monumental & 16.0 \\
\hline $\begin{array}{l}\text { 7. Metrópolis focalizadas en el } \\
\text { desarrollo local }\end{array}$ & Cuenca & 660500 & Avenida de las Américas & 20.4 \\
\hline
\end{tabular}

Nota: Categorización según (Cuadrado-Roura \& Fernández, 2005) y actualizado en base a "The world according to GaWC". Fuente: "Major agglomerations of the world" (2021); Google Earth. Recuperado 19 junio, 2020. 


\section{*.*vis revistainvi}

Finalmente, y en tercer lugar, el estudio se concentra en cuatro variables fundamentales para definir las centralidades urbanas: la historicidad -en el sentido de entender los procesos a lo largo del tiempo; la funcionalidad central que determina la capacidad y vocación propia de la centralidad-; la accesibilidad físicovirtual, que se refiere a los medios de integración, articulación y comunicación de las funciones dispersas; y la espacialidad, que es asumida por cada uno de estos procesos (zonas, nodos), en atención a lo que Bourdieu (1999, p. 119) afirma: "El lugar puede definirse claramente como el punto del espacio físico en que un agente o cosa están situados, "tienen lugar" o "existen."

\section{La reestructuración de las centralidades urbanas}

Desde fines del siglo XX, el patrón de urbanización de América Latina ha estado cambiando de ciudades nucleares -según jerarquía de rango-tamaño- a regiones urbanas inscritas en sistemas urbanos globales y pluriestatales (Carrión, 2012). La región urbana se origina con la ruptura de la limitante física de la mancha urbana propia de la ciudad central, a partir de la cual se proyecta una región urbana que se integra interurbanamente. A partir de esto, las relaciones de la ciudad con su entorno (esto es, de la centralidad con las nuevas periferias ${ }^{6}$ ) conducen a lo que Edward Soja (2005) ha denominado la "posmetrópoli.

Algunas teorías buscan explicar la metamorfosis de la configuración espacial de las ciudades desde los sistemas de acumulación y producción en el marco de la globalización. Allí se encuentran, por ejemplo, Garza et al. (2013), quienes plantean que las condiciones generales de producción (infraestructuras y servicios) son parte del andamiaje que permite comprender la organización y dinámica espacial de la ciudad. Así, los procesos de concentración y dispersión del territorio son resultado de las economías de aglomeración (concentración del capital) y, paralelamente, de las deseconomías de aglomeración (saturación de infraestructuras) (Singer, 1976; Santos y Proenca, 2020). Pero también Harvey (2005) retoma la teoría marxista para explicar las lógicas de localización a partir de los procesos de acumulación del capital que generan distintas estructuras geográficas y sociales (desposesión). Con este proceso también se alinean otras explicaciones, como las mutaciones demográficas, la reducción de la migración poblacional rural/urbana (Carrión y Cepeda, 2020) y la revolución científico-tecnológica en el campo de las comunicaciones (TICs) (Castells, 1997).

En este contexto aparecen nuevas centralidades urbanas -todas centralidades históricas- experimentando un proceso de pluralización, tanto en número como en modalidad, bajo una configuración que se muestra a través de tres expresiones principales:

- La primera, definida como centralidad fundacional ${ }^{7}$, posee la mayor densidad de antigüedad, en tanto fue el lugar donde se fundó la ciudad y comprendía, en su origen, la ciudad toda. Luego entra en un

5 Según Aristóteles (2015) traducido por Gabriel Livov Bernal: "Todas las cosas se definen por su función”.

6 La ruptura de la estructura espacial tradicional de la ciudad latinoamericana, compacta y con un centro único, y su reemplazo por una organización espacial difusa y con más de un núcleo, ha sido acompañada por el surgimiento de nuevos "artefactos" urbanos de integración (nodos).

7 Toda centralidad es histórica, independiente del momento de origen. 


\section{*.*vis revistainvi}

proceso de especialización funcional que se decanta con la localización de tres funciones centrales claves de aquel momento: la religiosa, la comercial y la administrativa pública y privada, además de aquellas provenientes del sector secundario de la economía (como la manufactura, la artesanía y la industria).

- La segunda, definida por la Escuela de Chicago como Central Business District (Sassen, 1995), fue el resultado de la concentración de las actividades de punta de la economía de aquella época, vinculadas al sector terciario: servicios para producir (finanzas); distribuir (comercio); recrear (cines); y consumir (restaurantes). En pocas palabras, un centro de negocios privados.

- La tercera expresión surge a partir del proceso de globalización, de la revolución científico-tecnológica (Cuarta Revolución Industrial) y la incidencia de capitales transnacionales (Pradilla Cobos, 2004). Se trata de una nueva modalidad: la de centralidad longitudinal, cuya función central proviene del sector terciario superior que se añade a las funciones preexistentes de la política, el comercio, la cultura y las finanzas. El sector terciario se refiere a las actividades económicas ubicadas entre la producción y el consumo; y el terciario superior, a las que ponen énfasis en la ciencia y el conocimiento inscritas en la economía global, esto es, a las actividades de las grandes corporaciones tipo Amazon, Google o Uber, que permiten articular estos centros -más específicamente, nodos-al sistema urbano mundial. Según Pradilla Cobos (2010), este sector evoluciona de manera polarizada; es decir, con un sector moderno de alta rentabilidad, mano de obra calificada y servicios privados; y otro informal, inestable e ilegal.

La urbanización de regiones -ciudad de ciudades- provoca la presencia de múltiples centralidades y periferias que demandan otras formas de articulación territorial. Para el efecto, la centralidad longitudinal se ancla en los dispositivos materiales preexistentes de accesibilidad y movilidad, como las calles, que deben reconstituirse con nuevos modos provenientes del mundo remoto (sociedad del conocimiento) (Carrión \& Cepeda, 2020) y de la localización de las actividades de punta del modelo de acumulación (funciones centrales). De esta manera, los antiguos callejones viales o avenidas, que servían para la integración de la ciudad zonificada por usos de suelo, se reestructuran y renuevan como corredores expresos y expeditos para integrar los flujos multivariados provenientes de la región urbana y del sistema urbano global.

Estos callejones viales se volvieron obsoletos frente al incremento de la demanda del parque automotor, de los requerimientos de las actividades económicas de punta y de la revolución científico-tecnológica. Por consiguiente, la mayor densidad física de actividades y de circulación produjo una renovación necesaria que, según Pradilla Cobos (2004), tomó tanto protagonismo que debilitó otras centralidades, atenuando a la vez los instrumentos de control y regulación pública de la ciudad. Es decir, se convirtió en un elemento vertebrador del urbanismo de proyectos (GPU) propio de una ciudad neoliberal (Carrión, 2021), que revitaliza callejones viales mediante promoción pública, pero de beneficio privado. Así, la centralidad longitudinal adopta una modalidad lineal mas no zonal como la de los centros anteriores ${ }^{8}$.

8 La centralidad entendida como punto funcional, según Von Thunen en 1820, es la base para el modelo de múltiples centralidades jerarquizadas de Christaler en 1966. El nivel de accesibilidad de una centralidad permite jerarquizar y determinar niveles de movimiento, así como ámbitos de influencia. 


\section{*.*vis revistainvi}

Secchi (2001) va más allá cuando expone que las grandes estructuras comerciales de las regiones urbanas se organizan a lo largo de carreteras y vías, con el resultado de un urbanismo extensivo y no concéntrico. Dicha dinámica significa el paso de una urbe con un solo tipo de centralidad a otra con múltiples centralidades, donde los corredores urbanos longitudinales toman protagonismo tanto por el flujo como por los lugares (nodos) (Hoyos, 2009).

Las centralidades lineales son atractoras y depositarias de actividades, flujos y conectividades. Es por esto que Panerai y Mangin (2002) plantean que la configuración de estas grandes vías enlaza barrios y aloja múltiples actividades urbanas, articulando centralidades zonales y lineales de forma simultánea.

La centralidad longitudinal se despliega en los denominados corredores urbanos con lógicas históricas superpuestas y multiescalares que combinan la estructuración de espacios de flujos y de lugares gracias a la alta densidad inmobiliaria, usos de suelo mixtos y al empleo diversificado, con énfasis en servicios privados de alta tecnología. Según Guevara (2007), estos elementos son fundamentales en la organización espacial de las ciudades actuales por ser distribuidores de equipamientos urbanos, articuladores de zonas y exhibidores comerciales que provocan efectos nocivos de movilidad y contaminación, servicios sociales limitados, alta especulación, elevadas rentas monopólicas y singulares desigualdades socio espaciales.

Los corredores urbanos además combinan su condición de centralidad física con la de nodo telemático gracias a los flujos virtuales, los cuales traen una accesibilidad novedosa. Los corredores se comportan, desde esta perspectiva, como hub o router ${ }^{9}$ por los que permanentemente entra y sale población, información, bienes, capitales y servicios. Es un cambio en la accesibilidad que proviene del nuevo sentido de las funciones centrales, y de la articulación con otras periferias y ciudades a través de medios remotos. En este caso, la accesibilidad no es solo física, vinculada a la infraestructura de transporte y movilidad humana, sino también telemática. Esto aporta a la integración de territorios, continuos-próximos y discontinuos-distantes, fuera de la tradicional organización e incidencia Estado-nacional correspondiente.

\section{La operatoria urbana de los corredores urbanos en el mundo}

La operatoria y configuración de los corredores y de las centralidades urbanas han variado cronológicamente según la predominancia de las funciones centrales y de los tipos de accesibilidades, definiendo estructuras espaciales específicas.

9 Hub es una categoría de la teoría de redes, un nodo de conexión con múltiples enlaces simultáneos de ingreso y egreso. Router, permite la interconexión de computadoras que funcionan en red. 


\section{HISTORICIDAD}

La historicidad de los corredores, como se observa en la Tabla 2, se caracteriza por su constante transformación, lo que los convierte también en testimonio de la historia de cada urbe. La mayoría de estos corredores ha transitado por las siguientes cinco coyunturas urbanas: la primera, originada en épocas precolombinas y fundacionales, cuando eran simplemente vías arrieras; una segunda sobreviene con el advenimiento del siglo XX, cuando surgen nuevas modalidades de movilidad (el automóvil); la tercera, con la presencia del urbanismo funcionalista y la arquitectura moderna (verticalización), las cuales permiten la concentración de nuevas funciones centrales; la cuarta, vinculada con la llegada del urbanismo neoliberal (GPUs); y la quinta, y final, con la formación de la denominada centralidad longitudinal.

Desde sus orígenes (en su mayoría previos al siglo XIX) fueron vías estratégicas para la movilidad intraurbana que integraban los polos extremos de la ciudad con la centralidad histórica de carácter zonal. Entre ellas están la Alameda O'Higgins en Santiago, Carrera Séptima en Bogotá y Avenida Guayaquil-10 de agosto en Quito. Pero, adicionalmente, se encuentran los que no atravesaban la centralidad urbana, aunque la circunvalaban, como son los casos del Paseo de la Reforma en México ${ }^{10}$, El Prado en La Paz o Avenida Libertador en Caracas. En la Figura 1 se puede observar la línea del tiempo de los corredores desde su fecha de origen.

\section{Figura 1.}

\section{Corredores urbanos de América Latina en el tiempo.}

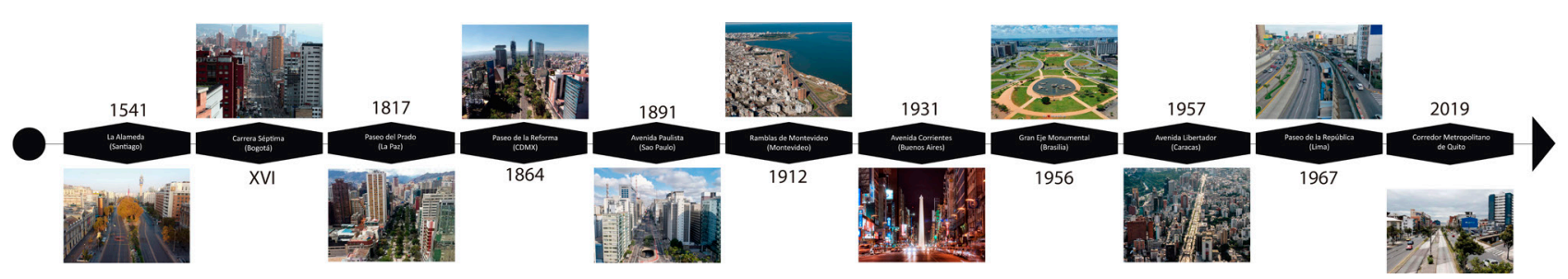

Fuente: Elaboración propia

10 El Paseo de la Reforma es la segunda centralidad más importante en Ciudad de México después del Centro histórico (Martínez, 2000). La modernización y localización de grandes empresas corporativas la convierten en un corredor terciario de alto alcance nacional y transnacional (Márquez-López, 2016). 
La mayoría de los corredores tienen orígenes precolombinos (El Prado, Carrera Séptima, Reforma, Alameda), pero también los hay más recientes, surgidos a principios del siglo XX, entre los cuales están las Ramblas de Montevideo (1912), que más bien son periféricas a la ciudad. Posteriormente, a mediados del Siglo XX; están los dos corredores brasileños: el Gran Eje Monumental en Brasilia que corresponde a una estructura planificada de ciudad (1960), mientras la Avenida Paulista de São Paulo, de una lógica de mercado (1950 y 1970). Los dos casos asumen la condición de centralidad, bajo lógicas distintas: el primero, del traslado de las funciones de capitalidad del gobierno nacional localizadas en Río de Janeiro hacia Brasilia y la segunda, de la concentración de los grandes capitales financieros, que la convierten en el centro de negocios de la ciudad y del país.

\section{Tabla 2.}

Transformación de los corredores urbanos en América Latina.

\begin{tabular}{|c|c|c|c|c|c|}
\hline $\begin{array}{l}\text { Corredor } \\
\text { Urbano }\end{array}$ & Siglo XIX Camino & $\begin{array}{l}\text { Inicio siglo XX } \\
\text { Infraestructura vial } \\
\text { (automóvil) }\end{array}$ & Mediados siglo XX (Verticalidad) & Fines siglo XX (GPUs) & Siglo XXI Centralidad \\
\hline \multicolumn{6}{|c|}{ Metrópolis continental avanzada } \\
\hline \multirow{5}{*}{$\begin{array}{l}\text { Paseo de la } \\
\text { Reforma }\end{array}$} & $\begin{array}{l}1864 \text { - Paseo del Emperador, } \\
\text { uso exclusivo emperadores }\end{array}$ & \multirow{5}{*}{$\begin{array}{l}1900 \text { - Circulación autos, } \\
\text { tranvías y ferrocarril } \\
\text { Cuernavaca. } \\
1901 \text { - Inicia desarrollo } \\
\text { inmobiliario acompañado } \\
\text { de mobiliario, alumbrado, } \\
\text { estatuas, monumentos, } \\
\text { ensanchamiento vías }\end{array}$} & \multirow{5}{*}{$\begin{array}{l}1933 \text {-Plan de Desarrollo } \\
\text { motivado por el desarrollo } \\
\text { inmobiliario en Lomas } \\
1940 \text { - Inicio de pavimentación } \\
1952 \text { - Edificios modernos, } \\
\text { redujeron las zonas peatonales }\end{array}$} & $\begin{array}{l}1968 \text { - Primera Línea del } \\
\text { Metro de la Ciudad }\end{array}$ & $\begin{array}{l}\text { 2003- Torre Mayor } \\
\text { edificio más alto AL }\end{array}$ \\
\hline & 1868 - Paseo Juárez y & & & \multirow{3}{*}{$\begin{array}{l}1970 \text { - Línea 2-3 del } \\
\text { Metro de la Ciudad y } \\
\text { Estación Transbordo } \\
\text { Hidalgo }\end{array}$} & \multirow{2}{*}{$\begin{array}{l}2000 \text { - Eje terciario, } \\
\text { densificación, eje de } \\
\text { metropolización }\end{array}$} \\
\hline & $\begin{array}{l}\text { posteriormente Paseo del } \\
\text { Degollado, uso público }\end{array}$ & & & & \\
\hline & \multirow{2}{*}{$\begin{array}{l}1872 \text { - Paseo de la Reforma } \\
\text { última denominación }\end{array}$} & & & & \multirow{2}{*}{$\begin{array}{l}2001 \text { - Programas } \\
\text { estímulos fiscales para } \\
\text { inversión y revitalización }\end{array}$} \\
\hline & & & & $\begin{array}{l}1991-\text { Proceso } \\
\text { modernización e } \\
\text { inversión }\end{array}$ & \\
\hline \multirow{4}{*}{$\begin{array}{l}\text { Avenida } \\
\text { Paulista }\end{array}$} & $\begin{array}{l}\text { Estrada Real Grandeza } \\
\text { camino antiguo }\end{array}$ & \multirow{3}{*}{$\begin{array}{l}\text { 1900- Avenida remodelada, } \\
\text { red electricidad y tranvía } \\
\text { eléctrico } \\
\text { 1910-1940 Centro de élite } \\
\text { paulista }\end{array}$} & \multirow{3}{*}{$\begin{array}{l}1950 \text { - Transformación de } \\
\text { palacetes residenciales en } \\
\text { comercios y oficinas. Proceso } \\
\text { de verticalización y arquitectura } \\
\text { moderna }\end{array}$} & $\begin{array}{l}1972 \text { - Avenida Paulista } \\
\text { reformada en ancho, }\end{array}$ & \multirow{4}{*}{$\begin{array}{l}\text { 2007-2015 - } \\
\text { Conformación de } 725 \\
\text { helipuertos }\end{array}$} \\
\hline & 1891- Avenida Acácias o & & & paisaje & \\
\hline & $\begin{array}{l}\text { Prado de São Paulo iniciativa } \\
\text { élite cafetera }\end{array}$ & & & $\begin{array}{l}\text { 1987- } 80 \text { Sedes de } \\
\text { Bancos }\end{array}$ & \\
\hline & $\begin{array}{l}\text { 1891- Primera línea de } \\
\text { tranvía, tracción animal }\end{array}$ & $\begin{array}{l}1920 \text { - Avenida Carlos de } \\
\text { Campos con nuevos patrones } \\
\text { urbanísticos, aislados del } \\
\text { frente de lote }\end{array}$ & $\begin{array}{l}\text { 1960-1970 - Construcción de } \\
\text { espigones con más } 30 \text { pisos, } \\
\text { distrito financiero }\end{array}$ & $\begin{array}{l}\text { 1990- Implantación } \\
\text { Metro, convirtiéndose } \\
\text { en influencia de escala } \\
\text { metropolitana }\end{array}$ & \\
\hline \multirow{3}{*}{$\begin{array}{l}\text { Avenida } \\
\text { Corrientes }\end{array}$} & 1700 - Sendero angosto & 1912- Línea B de Subte & \multirow{3}{*}{$\begin{array}{l}1947 \text { - Crecimiento inmobiliario } \\
\text { por los edificios de carácter } \\
\text { administrativo }\end{array}$} & & \multirow{3}{*}{$\begin{array}{l}\text { 2003-2018 } \\
\text { Reducción carriles y } \\
\text { ensanchamiento de } \\
\text { veredas }\end{array}$} \\
\hline & $\begin{array}{l}1822 \text { - Denominada Avenida } \\
\text { Corrientes }\end{array}$ & \multirow[t]{2}{*}{$\begin{array}{l}\text { 1931-1936 Ensanchada y } \\
\text { extendida en longitud }\end{array}$} & & & \\
\hline & $\begin{array}{l}\text { 1857- Primer ferrocarril dejo } \\
\text { de circular en } 1873\end{array}$ & & & & \\
\hline \multicolumn{6}{|c|}{ Metrópolis continental en proceso de desarrollo } \\
\hline \multirow{3}{*}{$\begin{array}{l}\text { Alameda } \\
\text { Libertador } \\
\text { General } \\
\text { Bernardo } \\
\text { O'Higgins }\end{array}$} & 1541 - Vertedero & \multirow{3}{*}{$\begin{array}{l}1900 \text { - Inicia dominio de } \\
\text { vehículos, buses colectivos. } \\
\text { Llegada tranvía eléctrico }\end{array}$} & & \multirow{3}{*}{$\begin{array}{l}1970 \text { - Fuerte } \\
\text { modificación con } \\
\text { primera línea Metro } \\
\text { Santiago }\end{array}$} & \multirow{3}{*}{$\begin{array}{l}\text { 2000- Aplicación } \\
\text { Transantiago }\end{array}$} \\
\hline & $\begin{array}{l}1818 \text { - Alameda de las } \\
\text { Delicias }\end{array}$ & & & & \\
\hline & $\begin{array}{l}1897 \text { - Extensión } \\
\text { longitudinal con Estación } \\
\text { ferroviaria }\end{array}$ & & & & \\
\hline
\end{tabular}




\begin{tabular}{|c|c|c|c|c|c|}
\hline \multirow{3}{*}{$\begin{array}{l}\text { Carrera } \\
\text { Séptima }\end{array}$} & $\begin{array}{l}\text { XVI - Camino de la Carrera } \\
\text { o calle real }\end{array}$ & $\begin{array}{l}1900 \text { - Carrera Séptima } \\
\text { ensanchamiento eje vial } \\
\text { angosto, sistema eléctrico }\end{array}$ & $\begin{array}{l}\text { 1948-1958 - Lugar de } \\
\text { importantes hechos políticos de } \\
\text { la ciudad }\end{array}$ & $\begin{array}{l}1979 \text { - Edificio más } \\
\text { alto de Colombia Torre } \\
\text { Colpatria }\end{array}$ & $\begin{array}{l}2000 \text { - Diversidad de } \\
\text { actividades y altos } \\
\text { problemas de vialidad }\end{array}$ \\
\hline & \multirow{2}{*}{$\begin{array}{l}1884 \text { - Carrera Séptima } \\
\text { circula la línea más antigua } \\
\text { de tranvía de la ciudad }\end{array}$} & & \multirow[t]{2}{*}{$\begin{array}{l}1950 \text { - Ensanchamiento de vía y } \\
\text { crecimiento de tráfico automotor }\end{array}$} & & $\begin{array}{l}2014 \text { - Rehabilitación y } \\
\text { peatonización }\end{array}$ \\
\hline & & & & & $\begin{array}{l}2019 \text { - Proyecto La } \\
\text { Nueva Séptima }\end{array}$ \\
\hline $\begin{array}{l}\text { Avenida } \\
\text { Libertador }\end{array}$ & & & $\begin{array}{l}\text { 1957-1965 Construida por } \\
\text { iniciativa del presidente Rómulo } \\
\text { Betancourt }\end{array}$ & $\begin{array}{l}1990 \text { - Sede de trabajo } \\
\text { sexual de la ciudad }\end{array}$ & $\begin{array}{l}2011 \text { - Construcción } \\
\text { Misión Vivienda y } \\
\text { elimina trabajo sexual de } \\
\text { la zona }\end{array}$ \\
\hline \multicolumn{6}{|c|}{ Metrópolis nacionales avanzadas } \\
\hline \multirow[b]{2}{*}{$\begin{array}{l}\text { Ramblas de } \\
\text { Montevideo }\end{array}$} & & $\begin{array}{l}\text { 1906-1912 Plan Regulador de } \\
\text { Montevideo }\end{array}$ & \multirow{2}{*}{$\begin{array}{l}1946 \text { - Boom inmobiliario } \\
\text { principalmente Rambla Pocitos, } \\
\text { marcan altura de urbanización } \\
\text { de la ciudad }\end{array}$} & \multirow{2}{*}{$\begin{array}{l}1986 \text { - Declarada } \\
\text { Monumento histórico } \\
\text { nacional }\end{array}$} & \multirow{2}{*}{$\begin{array}{l}\text { 2019-2020 Proyecto } \\
\text { Viaducto Ramblas } \\
\text { Portuarias }\end{array}$} \\
\hline & & $\begin{array}{l}1923 \text {-1925 Se crea Comisión } \\
\text { Financiera para iniciar } \\
\text { Ramblas Montevideo }\end{array}$ & & & \\
\hline \multirow{2}{*}{$\begin{array}{l}\text { Paseo de la } \\
\text { República }\end{array}$} & \multirow{2}{*}{$\begin{array}{l}1858 \text { - Línea férrea conexión } \\
\text { Lima y Chorrillos } \\
1868 \text { - Paseo de la República }\end{array}$} & & \multirow{2}{*}{$\begin{array}{l}\text { 1966-1969 Paseo de la República, } \\
\text { inicia con construcción vía } \\
\text { expresa, primer y segundo tramo, } \\
\text { poca circulación vehicular }\end{array}$} & $\begin{array}{l}1980 \text { - Se añaden a la } \\
\text { vía expresa jardines con } \\
\text { publicidad, murales }\end{array}$ & $\begin{array}{l}2006 \text { - Construcción } \\
\text { sistema tránsito rápido } \\
\text { Metropolitano }\end{array}$ \\
\hline & & & & $\begin{array}{l}1999 \text { - Construcción } \\
\text { edificios de altura y } \\
\text { financieros }\end{array}$ & $\begin{array}{l}2012 \text { - Última etapa de } \\
\text { interés público }\end{array}$ \\
\hline \multirow{2}{*}{$\begin{array}{l}\text { Avenida } \\
\text { Guayaquil - } \\
10 \text { Agosto }\end{array}$} & \multirow{2}{*}{$\begin{array}{l}\text { Siglo XIX - Camino Real } \\
\text { camino de carrozas }\end{array}$} & \multirow[t]{2}{*}{1914 - Tranvía de Quito } & $\begin{array}{l}1950 \text { - Se convierte en escenario } \\
\text { de protestas }\end{array}$ & \multirow{2}{*}{$\begin{array}{l}\text { 1980-2000 Construcción } \\
\text { pasos a desnivel y } \\
\text { edificios de gran altura } \\
1994 \text { - Inicia } \\
\text { construcción Trolebús }\end{array}$} & \multirow{2}{*}{$\begin{array}{l}\text { 2011- Actividad } \\
\text { comercial, flujo de } \\
\text { personas y vehículos } \\
\text { 2017-2020 Fuerte } \\
\text { proceso de vaciamiento }\end{array}$} \\
\hline & & & $\begin{array}{l}1970 \text { - Edificio Benalcázar fue el } \\
\text { más alto de Quito con } 22 \text { pisos }\end{array}$ & & \\
\hline \multicolumn{6}{|c|}{ Metrópolis nacionales con bajo nivel de desarrollo } \\
\hline \multirow{3}{*}{$\begin{array}{l}\text { Paseo del } \\
\text { Prado }\end{array}$} & \multirow{3}{*}{$\begin{array}{l}1817 \text { - Idea Gobernador Juan } \\
\text { Sánchez Lima } \\
\text { 1828-1909 Adecuaciones } \\
\text { en banquetas, jardines e } \\
\text { inmobiliario urbano }\end{array}$} & $\begin{array}{l}1909 \text { - Inauguración Tranvías } \\
\text { de la Paz }\end{array}$ & \multirow{3}{*}{$\begin{array}{l}1950 \text { - Cierre tranvías y aumento } \\
\text { tráfico vehicular y crecimiento } \\
\text { urbanístico }\end{array}$} & \multirow{3}{*}{$\begin{array}{l}1970 \text { - Boom edificios } \\
\text { al derrumbar casas } \\
\text { coloniales }\end{array}$} & \\
\hline & & \multirow{2}{*}{$\begin{array}{l}1925 \text { - Plantan árboles y } \\
\text { asfalta vía } \\
1930 \text { - Entubamiento del Río } \\
\text { Choqueyapu }\end{array}$} & & & \\
\hline & & & & & \\
\hline \multirow[b]{2}{*}{$\begin{array}{l}\text { Gran Eje } \\
\text { Monumental }\end{array}$} & & & 1956 - Inicio del proyecto & \multirow{2}{*}{$\begin{array}{l}1987 \text { - Declarado } \\
\text { patrimonio mundial por } \\
\text { UNESCO }\end{array}$} & \\
\hline & & & $\begin{array}{l}1960 \text { - Transfieren órganos } \\
\text { gubernamentales desde Río de } \\
\text { Janeiro }\end{array}$ & & \\
\hline
\end{tabular}

Fuente: Elaboración por autor con base en Alcocer (2000), Carmona (2002), Casas (2013), Chini (2019), Gruschetsky (2009), Hidalgo (2015), Marechal (2013), Márquez-López (2016), Oliveira (1998) y Priore Lima (2014). 


\section{*.*vis revistainvi}

A partir del pasaje del siglo XIX al XX, se vive una metamorfosis generalizada gracias a las nuevas modalidades de transporte del automóvil privado (Ramblas), tranvía (Paulista, O’Higgins, El Prado), tren (Corrientes, Reforma, República) y buses (Guayaquil-10 de agosto). Por este motivo se rediseña la vialidad (El Prado, Reforma, Alameda), con la ampliación del recorrido, el ajardinamiento y la implantación de equipamientos urbanos, siguiendo el emblemático caso de los Campos Elíseos de París, el cual se convirtió en un ícono o marca de la ciudad y en un paradigma a ser emulado, por su concepción urbanística.

A esta transformación se suma la entrada del urbanismo funcionalista y la arquitectura moderna, propias del desarrollo de las estructuras de acero, hormigón armado y de los sistemas de circulación vertical (ascensores). De esta manera, se impulsa el soporte inmobiliario en altura, que permitió sentar las bases del espacio operacional. Este, desde mediados del siglo XX, sería el que atraería las funciones centrales del comercio y las finanzas, constituyendo la segunda modalidad de centralidad urbana: el Central Business District.

En los procesos de expansión y modernización de las urbes, los corredores fueron causa y efecto de la tridimensionalidad que constituyó el nuevo carácter de la centralidad. En lo alto, la verticalización; en lo ancho, el ensanche y en lo largo la expansión; tres dimensiones inscritas en el sentido del nuevo urbanismo. Aquí el terciario superior es la función central, que demanda el cambio en las zonificaciones (usos de suelo, densidades, alturas) y una inversión especializada en las condiciones generales de la producción (infraestructuras), elementos que configuran el urbanismo de proyectos (Carrión, 2021). Pero también se convierten en el estímulo para el incremento de la densidad de población, de bienes inmobiliarios y de actividades. Estos, a su vez, pasan a ser los elementos motores de los problemas de congestión vehicular y contaminación ambiental, demandando nuevos modos de movilidad masiva -como el Metro, los BRT y los VLT- inscritos en la ciudad neoliberal que despega en el cambio de este siglo XXI.

En el último siglo se vive la consolidación de los corredores urbanos como centralidad longitudinal, marcadas por las nuevas temporalidades -como la renovación-, que siempre se reestructuran de acuerdo a las funciones que demandan las urbes, acompañadas de dinámicas de financiarización, especulación y cambio de población; este fenómeno no ocurre con las centralidades tradicionales o clásicas, que viven procesos de decadencia ${ }^{11}$.

Pero, así como se configuran en nodos de articulación mundial, en etapas de auge, actualmente empiezan experimentar procesos de declive por el desarrollo significativo de las nuevas infraestructuras telemáticas. Estas trasladan la lógica de base material de la ciudad (infraestructuras) a la de plataformas remotas, produciendo dos efectos: por un lado, que la accesibilidad provenga más de las nuevas autopistas virtuales (circuitos o redes globales) que de la vialidad tradicional (ejes viales) y, por otro, que las funciones centrales del comercio, las finanzas y la cultura pierdan localización física, reduciéndose los espacios de estas funciones en las zonas y líneas centrales de las ciudades.

Desde esta perspectiva, al analizar el precio de los bienes inmuebles en los corredores, como se observa en la Tabla 3, se debe decir que los precios más altos están relacionados a la jerarquía metropolitana de cada

11 Por eso el uso del prefijo "re-" delante de algunos conceptos de la arquitectura o del urbanismo: rehabilitar, reconstruir, revitalizar, restaurar, entre muchos otros. 
ciudad y al tipo de especialización funcional que tienen -con excepción de Corrientes en Buenos Aires y de Libertador en Caracas, donde la caída de la paridad frente al dólar en los dos países marca su devaluación. Pero también están los casos de Quito, donde el corredor vive una crisis fuerte, y de Brasilia, donde el peso de la función gubernamental impide el funcionamiento del mercado inmobiliario privado.

\section{Tabla 3.}

Precio promedio $m^{2}$ bienes inmuebles.

\begin{tabular}{|c|c|c|}
\hline Corredor Urbano & Precio promedio $\mathrm{m}^{2}$ 08-2020 & Precio promedio $\mathrm{m}^{2}$ 01-2021 \\
\hline \multicolumn{3}{|c|}{ Metrópolis continental avanzada } \\
\hline Paseo de la Reforma & $\$ 4,600.00$ & $\$ 4,300.00$ \\
\hline Avenida Paulista & $\$ 5,000.00$ & $\$ 3,400.00$ \\
\hline Avenida Corrientes & $\$ 3,000.00$ & $\$ 1,500.00$ \\
\hline \multicolumn{3}{|c|}{ Metrópolis continental en proceso de desarrollo } \\
\hline Alameda Libertador General Bernardo O'Higgins & $\$ 2,500.00$ & $\$ 2,100.00$ \\
\hline Carrera Séptima & $\$ 1,800.00$ & $\$ 2,000.00$ \\
\hline Avenida Libertador & $\$ 1.00$ & $\$ 1.00$ \\
\hline \multicolumn{3}{|c|}{ Metrópolis nacionales avanzadas } \\
\hline Ramblas de Montevideo & $\$ 2,500.00$ & $\$ 2,800.00$ \\
\hline Paseo de la República & $\$ 2,000.00$ & $\$ 1,900.00$ \\
\hline Avenida Guayaquil - Av. 10 de Agosto & $\$ 1,500.00$ & $\$ 1,000.00$ \\
\hline \multicolumn{3}{|c|}{ Metrópolis nacionales con bajo nivel de desarrollo } \\
\hline Paseo del Prado & $\$ 900.00$ & $\$ 800.00$ \\
\hline Gran Eje Monumental & $\$ 2,300.00$ & $\$ 1,950.00$ \\
\hline
\end{tabular}

Fuente: Elaboración por autor con base en ponderación de datos de bienes raíces (CDMX, icasas; Sao Paulo, vivareal; Buenos Aires, zonaprop; Santiago, zo ominmobiliario; Bogotá, trovit; Caracas, conlallave; Montevideo, infocasas; Lima, trovit; Quito, plusvalía; La Paz, boliviainmobiliaria; Brasilia, wimoveis). 
En segundo lugar, dos aspectos se aprecian con la caída de los precios de los bienes inmobiliarios: i) uno de carácter coyuntural (con una pérdida en los precios inmobiliarios de en un $17 \%$ en solo cinco meses, explicable por la reducción de la densidad de interacción social y de la crisis económica, surgidas por el impacto del COVID-19); y ii) otro referido a la condición estructural, relacionada a la declinación de este tipo de centralidad debido al auge de la tecnología virtual que estaría produciendo la deslocalización, relocalización e incluso la alocalización del trabajo y los servicios (Carrión \& Cepeda, 2020). Esto es, podría estar abriéndose una nueva fase en la centralidad: isu fin?

\section{FUNCIONALIDAD}

En cuanto a las funciones centrales que definen la condición de la centralidad urbana, se puede afirmar que tienen una presencia diversificada; aunque en muchos casos con similitudes y especializaciones. Como se observa en la Tabla N 2, todos los corredores son históricos, lo cual los dota de una función monumental; pues en ellos hay presencia de numerosos edificios de alta carga conmemorativa, como acontece en Paseo de la Reforma o en la Av. Bernardo O'Higgins. Así, también en la Tabla N 4 se analiza el predominio de la actividad económica internacional que les otorga una función global, como ocurre en la Avenida Paulista con los espigones de firmas transnacionales.

\section{Tabla 4.}

Transformación de funciones de corredores urbanos de América Latina.

\begin{tabular}{lll} 
Corredor Urbano & Funcionalidad & Actualidad \\
\cline { 2 - 3 } & Origen & \multicolumn{1}{c}{ Metrópolis continental avanzada } \\
\hline Paseo de la Reforma & Residencias lujosas, aristocráticas & $\begin{array}{l}\text { Espacio de manifestaciones sociales, deportivas, políticas, } \\
\text { culturales y alta carga simbólica } \\
\end{array}$ \\
& & $\begin{array}{l}\text { Edificios más altos de la ciudad con actividades económicas de } \\
\text { punta }\end{array}$ \\
\hline Avenida Paulista & Zona residencial de élite cafetera & $\begin{array}{l}\text { Mayor centro financiero de Latinoamérica, edificios de mayor } \\
\text { densidad constructiva y altura de la ciudad }\end{array}$ \\
& de la sociedad paulista & $\begin{array}{l}\text { Predominio actividades residenciales, comerciales, culturales y } \\
\text { financieras }\end{array}$ \\
\hline Avenida Corrientes & Sendero de tierra & $\begin{array}{l}\text { Centro financiero, administrativo, comercial, cultural y } \\
\text { entretenimiento mundial «la calle que nunca duerme» }\end{array}$ \\
& & Metrópolis continental en proceso de desarrollo
\end{tabular}




\begin{tabular}{|c|c|c|}
\hline $\begin{array}{l}\text { Alameda Libertador } \\
\text { General Bernardo } \\
\text { O'Higgins }\end{array}$ & $\begin{array}{l}\text { Cauce norte, abastecedor de agua } \\
\text { y cauce sur vertedero de residuos }\end{array}$ & $\begin{array}{l}\text { Mayor conexión urbana, gran actividad comercial y } \\
\text { monumental en un bandejón central }\end{array}$ \\
\hline Carrera Séptima & Camino indígena a Usaquén & $\begin{array}{l}\text { Eje representativo histórico, cultural, educativo, político, } \\
\text { económico, recreacional, comercial }\end{array}$ \\
\hline Avenida Libertador & Vía de conexión & $\begin{array}{l}\text { Atraviesa distritos financieros, culturales, comerciales, } \\
\text { turísticos y residenciales }\end{array}$ \\
\hline \multicolumn{3}{|c|}{ Metrópolis nacionales avanzadas } \\
\hline \multirow[t]{2}{*}{$\begin{array}{l}\text { Ramblas de } \\
\text { Montevideo }\end{array}$} & $\begin{array}{l}\text { Eje arbolado para contemplar el } \\
\text { Río de la Plata }\end{array}$ & $\begin{array}{l}\text { Actividades de balneario con } 20 \text { playas a lo largo y actividades } \\
\text { surf, canotaje, remo, deporte de competencia }\end{array}$ \\
\hline & & $\begin{array}{l}\text { Lugar de mayor desarrollo residencial más elegante y moderno } \\
\text { de la ciudad y fuerte significado cultural y patrimonial, } \\
\text { símbolo de identidad }\end{array}$ \\
\hline \multirow{2}{*}{$\begin{array}{l}\text { Paseo de la } \\
\text { República }\end{array}$} & Conexión Lima con Chorrillos & Zona financiera, edificios de gran altura e influencia regional. \\
\hline & & $\begin{array}{l}\text { Desarrolladores inmobiliarios de gran atractivo por su sistema } \\
\text { de transporte }\end{array}$ \\
\hline Avenida Guayaquil & $\begin{array}{l}\text { Principal acceso al Centro } \\
\text { histórico }\end{array}$ & $\begin{array}{l}\text { Localización de edificios gubernamentales, históricos y } \\
\text { actualmente } 110 \text { edificios desocupados }\end{array}$ \\
\hline \multicolumn{3}{|c|}{ Metrópolis nacionales con bajo nivel de desarrollo } \\
\hline Paseo del Prado & Vía límite de la ciudad & $\begin{array}{l}\text { Arteria central donde se localiza monumentos, sitios } \\
\text { históricos, bancos, restaurantes y museos }\end{array}$ \\
\hline $\begin{array}{l}\text { Gran Eje } \\
\text { Monumental }\end{array}$ & $\begin{array}{l}\text { Edificios de carácter } \\
\text { gubernamental }\end{array}$ & Eje monumental es una espina del centro político \\
\hline
\end{tabular}

Fuente: Elaboración por autor con base en Alcocer (2000), Carmona (2002), Casas (2013), Chini (2019), Gruschetsky (2009), Hidalgo (2015), Marechal (2013), Márquez-López (2016), Oliveira (1998) y Priore Lima (2014).

Estas funciones conducen a una especialización del corredor, variable en el tiempo. Inicialmente fueron caminos de conexión y de uso residencial, con un importante componente de desigualdad que se verifica con la mejor localización de las familias adineradas respecto al centro fundacional y la desmedrada ubicación de las de menos ingresos respecto a la centralidad. En la actualidad esta tendencia se mantiene (Las Ramblas) bajo una doble lógica diferencial: la gentrificación elitiza el contenido social (Avenida Paulista, Reforma), y el cambio de usos de suelo conduce a las actividades más rentables (El Prado, Carrera Séptima), como son las funciones turísticas, comerciales y financieras.

Pero también hay casos de especialización de la función cultural, concentrada en la Carrera Séptima o Avenida Corrientes, con teatros, cafeterías y universidades. Además, no puede quedar atrás la exclusividad de la función gubernamental en el Gran Eje Monumental en Brasilia, con el peso de las actividades públicas administrativas del gobierno federal; algo similar -aunque con las diferencias del caso- al National Mall en Washington. 
En estos corredores confluyen centros comerciales, edificios corporativos, sedes bancarias, universidades, hoteles, restaurantes, teatros, administración pública y privada, el sector inmobiliario, monumentos, museos, comercios y las oficinas de servicios terciarios. Es el espacio principal del capital inmobiliario, con costos de suelo relacionados al ranking de la urbe y apoyados en la tesis de la ciudad compacta, que impulsa procesos de recambio poblacional y de actividades. Estas arterias concentran buena parte de la oferta de trabajo, confluencia de población económicamente activa y la mayor densidad de riqueza de la ciudad. Pero su conformación, genera una serie de externalidades negativas, como son los altos costos de suelo (que terminan impulsando la gentrificación e incrementando las desigualdades no solo al interior de las ciudades, sino también en las relaciones entre ellas), y altas tasas de congestión y tráfico.

Estas entradas configuran el singular carácter simbólico que siempre ha tenido la centralidad, aunque en este último período sea mucho más rutilante. Esta condición simbólica permite la integración social y la pertenencia cultural, según los ámbitos intra e interurbanos.

\section{ACCESIBILIDAD}

La accesibilidad es fundamental en la configuración de cualquier centralidad urbana, debido a que a través de ella se logra que las funciones centrales definan sus radios de influencia y de acción. Para esto es importante su ubicación dentro de la estructura urbana, que generalmente corresponde a lugares céntricos (excepción del caso de las Ramblas en Montevideo). Pero también mucho tienen que ver los medios de transporte y la manera en que han evolucionado; tanto es así que los corredores han sido el escenario de la innovación en cada época, como se observa la Tabla N 5. El salto del transporte peatonal o tracción animales hacia sistemas motorizados se produjo a inicios del siglo XIX y, con ello, la vialidad automotora tomó relevancia. 
Tabla 5.

Transformación de accesibilidad de corredores urbanos de AL.

\begin{tabular}{|c|c|c|c|}
\hline \multirow{2}{*}{$\begin{array}{l}\text { Corredor } \\
\text { Urbano }\end{array}$} & \multirow[t]{2}{*}{ Localización } & \multicolumn{2}{|l|}{ Accesibilidad } \\
\hline & & Origen & Actualidad \\
\hline \multicolumn{4}{|c|}{ Metrópolis continental avanzada } \\
\hline $\begin{array}{l}\text { Paseo de la } \\
\text { Reforma }\end{array}$ & $\begin{array}{l}\text { Desde Santa Fe -nodo global- } \\
\text { hasta Tepito -mercado popular-, } \\
\text { bordeando el Centro Histórico y la } \\
\text { zona turística, comercial y financiera }\end{array}$ & $\begin{array}{l}\text { Camino de Emperadores } \\
\text { y luego abierto a } \\
\text { movilidad peatonal }\end{array}$ & $\begin{array}{l}\text { Metro bajo tierra y Metro Bus (BRT) y } \\
\text { bicicleta, helipuertos. } \\
265000 \text { pasajeros transitan } \\
\text { diariamente. }\end{array}$ \\
\hline $\begin{array}{l}\text { Avenida } \\
\text { Paulista }\end{array}$ & $\begin{array}{l}\text { Desde Pacaembú hasta la Cima } \\
\text { Paulista }\end{array}$ & $\begin{array}{l}\text { Primera vía pública } \\
\text { asfaltada }\end{array}$ & $\begin{array}{l}\text { Movimiento intenso de carros y } \\
\text { autobuses. Alta demanda Metro } \\
\text { (4estaciones). Mejora la accesibilidad } \\
\text { con helipuertos en edificios. }\end{array}$ \\
\hline $\begin{array}{l}\text { Avenida } \\
\text { Corrientes }\end{array}$ & $\begin{array}{l}\text { Desde el nodo global de Puerto } \\
\text { Madero, pasando por Av. } 9 \text { de Julio } \\
\text { hasta el Cementerio de Chacarita }\end{array}$ & $\begin{array}{l}\text { Primer tren de Argentina } \\
\text { y tranvía }\end{array}$ & $\begin{array}{l}\text { Actualidad } 35 \text { líneas de colectivos, } \\
\text { dos estaciones de tren y } 17 \text { estaciones } \\
\text { de subte. Proyecto piloto de } \\
\text { peatonización parcial y nocturna. }\end{array}$ \\
\hline \multicolumn{4}{|c|}{ Metrópolis continental en proceso de desarrollo } \\
\hline $\begin{array}{l}\text { Alameda } \\
\text { Libertador } \\
\text { General } \\
\text { Bernardo } \\
\text { O'Higgins }\end{array}$ & $\begin{array}{l}\text { Desde Av. Presidente Salvador } \\
\text { Allende hasta Av. Miguel Ramírez }\end{array}$ & $\begin{array}{l}\text { Paseo con estatuas y } \\
\text { monumentos }\end{array}$ & $\begin{array}{l}\text { Localiza el Metro de Santiago y } \\
\text { columna vertebral de transporte } \\
\text { privado y público. } \\
\text { Transantiago y Red Metropolitana de } \\
\text { movilidad varias líneas de bus con } \\
\text { Metro Santiago. }\end{array}$ \\
\hline $\begin{array}{l}\text { Carrera } \\
\text { Séptima }\end{array}$ & $\begin{array}{l}\text { Desde Chía hasta Río Fucha en Santa } \\
\text { Ana Sur }\end{array}$ & & $\begin{array}{l}\text { Alta circulación vehicular, peatonal, } \\
\text { transporte público. Una estación de } \\
\text { Transmilenio. } 26 \mathrm{~km} / \mathrm{h} \text { promedio y } 32 \\
000 \text { pasajeros por hora }\end{array}$ \\
\hline $\begin{array}{l}\text { Avenida } \\
\text { Libertador }\end{array}$ & Desde Santa Rosa hasta Bello Campo & Eje conexión & $\begin{array}{l}\text { Dos niveles, vía rápida por debajo } \\
\text { y por arriba dos ejes de tránsito } \\
\text { vehicular y puentes peatonales }\end{array}$ \\
\hline \multicolumn{4}{|c|}{ Metrópolis nacionales avanzadas } \\
\hline $\begin{array}{l}\text { Ramblas de } \\
\text { Montevideo }\end{array}$ & $\begin{array}{l}\text { Desde Escollera Sarandí hasta } \\
\text { Arroyo Carrasco }\end{array}$ & Eje Arbolado & $\begin{array}{l}\text { Eje con tres fajas, céntrica circulación } \\
\text { vehicular y dos laterales de } \\
\text { circulación peatonal. }\end{array}$ \\
\hline
\end{tabular}




\begin{tabular}{l|l|l|l}
\hline $\begin{array}{l}\text { Paseo de la } \\
\text { República }\end{array}$ & $\begin{array}{l}\text { Desde Lince hasta Barranco con 66 } \\
\text { cuadras }\end{array}$ & Línea férrea & $\begin{array}{l}\text { Principal sistema de movilidad } \\
\text { BRT Metropolitano, terminales de } \\
\text { transporte interprovincial. } \\
\text { Conforma ramblas de acceso a vía } \\
\text { expresa, dos carriles vía normal y tres } \\
\text { carriles vía rápida }\end{array}$ \\
\hline $\begin{array}{l}\text { Avenida } \\
\text { Guayaquil } \\
\text { hasta Avenida Maldonado (Sur) }\end{array}$ & $\begin{array}{l}\text { Desde Avenida 10 de agosto (Norte) } \\
\text { Paseo del } \\
\text { Prado }\end{array}$ & $\begin{array}{l}\text { Desde Avenida Mariscal Santa Cruz } \\
\text { hasta Ruta Nacional }\end{array}$ & $\begin{array}{l}\text { Vía sobre Río } \\
\text { Choqueyapu } \\
\text { buses de transporte público y } \\
\text { vehículos privados, alto tránsito y } \\
\text { aglomeraciones. }\end{array}$ \\
\hline $\begin{array}{l}\text { Gran Eje } \\
\text { Monumental }\end{array}$ & $\begin{array}{l}\text { Desde Bosque de Constituyentes } \\
\text { hasta Regimiento de la Caballería de } \\
\text { Guardia }\end{array}$ & $\begin{array}{l}\text { Bulevar verde, la avenida } \\
\text { tiene seis carriles con dos } \\
\text { autopistas de 250 metros } \\
\text { de ancho }\end{array}$ & $\begin{array}{l}\text { Misma conformación desde su } \\
\text { planificación por su condición de } \\
\text { Plan de ciudad }\end{array}$ \\
\hline
\end{tabular}

Fuente: Elaboración por autor con base en Alcocer (2000), Carmona (2002), Casas (2013), Chini (2019), Gruschetsky (2009), Hidalgo (2015), Marechal (2013), Márquez-López (2016), Oliveira (1998) y Priore Lima (2014).

Así tenemos que el automóvil privado y el tranvía son los primeros en dar jerarquía a las vías urbanas. Entre ellas se encuentran los orígenes de los llamados corredores urbanos, siempre concebidos para integrar los límites externos de la ciudad con sus centralidades, lo cual hoy se hace más evidente con la lógica de la urbanización regional. Tanto el transporte individual del automóvil como el colectivo requerían de infraestructuras adecuadas que debieron ser diseñadas para el efecto -como lo evidencian el Paseo del Prado en La Paz, Avenida Guayaquil-10 de agosto en Quito y Corrientes en Buenos Aires-, entre otros.

Posteriormente, con el ingreso de los sistemas masivos de transporte, bajo suelo o de superficie, cambian sustancialmente estos viaductos. La primera fase de los metros en América Latina se inicia en Buenos Aires en 1913, pero recién toma fuerza en el último tercio del siglo con la entrada en la Alameda Bernardo O'Higgins (de Santiago) y Reforma (de Ciudad de México). Y luego, ya en este siglo, en Av. Paulista el primero y Guayaquil-10 de agosto el más reciente. En el medio, aparecen los llamados Bus Rapid Transit (BRT) que tienen una gran presencia en la articulación del transporte del conjunto de la ciudad con el Transantiago en Alameda O’Higgins, Trasnmilenio en la Carrera Séptima de Bogotá y Trolebús en Guayaquil-10 de agosto. En cuanto el nivel de congestión, Carrera Séptima, Paseo de la Reforma y Avenida Paulista son las más complicadas en América Latina. A pesar de que la mayoría de los corredores tiene líneas de metro y/o de bus rápido, su accesibilidad es relativa, por lo que ciertas ciudades han buscado una combinación con programas aéreos (helipuertos) y movilidad alternativa (bicicleta, peatonalización, scooters). 


\section{粼 revistainvi}

Si bien la rectoría de la producción de los corredores urbanos fue pública, su construcción y apropiación fueron privadas, debido a que se inscribieron en la lógica del llamado urbanismo de proyectos, que sustituyó a la planificación urbana. El tipo más significativo de acción pública es el Gran Eje Monumental, que responde a un plan urbano de ámbito nacional. Su producción es iniciativa de niveles de gobierno distintos: la Avenida Bernardo O'Higgins fue construida por el gobierno nacional; la Avenida Paulista, por el Estado de São Paulo, y la Carrera Séptima, por el gobierno municipal, pero su desarrollo se debe a la inversión privada. De tal manera, estas infraestructuras fueron diseñadas para el automóvil y luego, según cada coyuntura, para las nuevas modalidades del transporte de punta; hasta llegar al momento actual, cuando aparecen BRTs, metros, helipuertos y el auge de las nuevas formas de transporte no motorizado.

\section{ESPACIALIDAD}

El cambio formal y de contenido de la centralidad se explicita a partir de lo que Castells (1974) plantea respecto de la urbanización, en términos del tránsito de los "espacios de los lugares al de los flujos". Los espacios de la centralidad urbana clásica se transforman, siguiendo una metáfora geométrica, desde el espacio-lugar interpretado como un punto -centro de un plano-, al de un espacio-flujo como una sucesión de puntos o nodos continuos, como se puede ver en la Figura 2.

\section{Figura 2.}

Corredores de Metrópolis continentales en proceso de desarrollo.
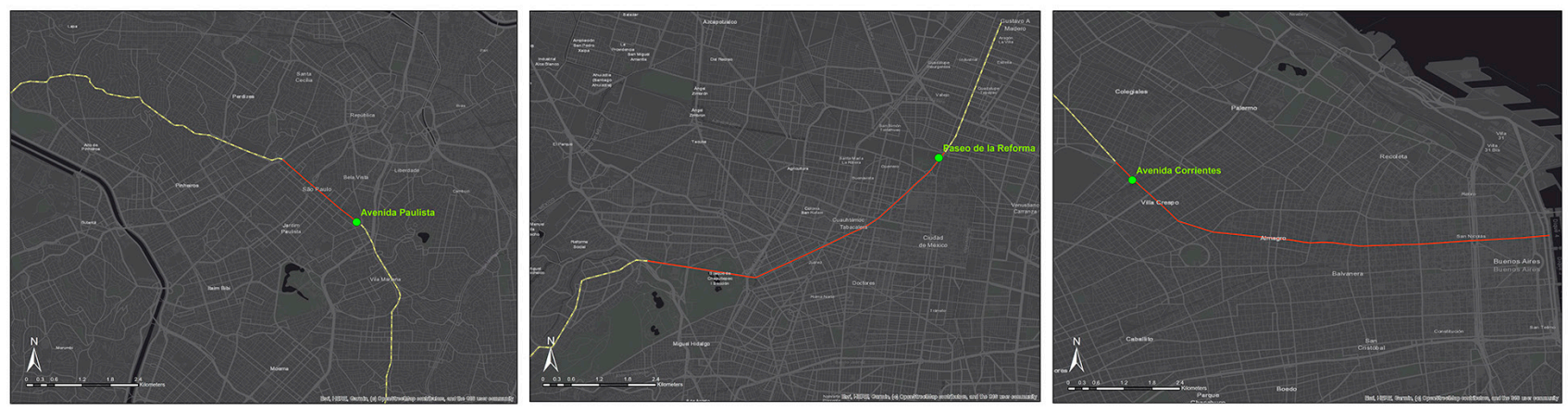

Fuente: Elaboración propia 


\section{粼 revistainvi}

Es mediante esta relación entre los puntos (línea) que se especifica la alteridad, la alta carga simbólica y la interacción social y económica que portan. En otras palabras, la centralidad ya no es exclusivamente una zona -a la manera de un punto equidistante a todos los puntos de una circunferencia- sino una línea que se constituye a partir de nodos localizados a lo largo de un trazo extendido. Y en un próximo futuro, una que se desplazará del espacio material al ciberespacio.

Territorialmente los corredores estructurados como centralidades longitudinales, se expanden como filamentos articuladores. En la Figura 3 se observa su localización que conecta la estructura productiva con los territorios próximos. Además, muestra la centralidad longitudinal articulada a la región urbana. En todas las jerarquías se observa la misma dinámica que se expande longitudinalmente y luego conecta a los territorios próximos.

\section{Figura 3.}

Centralidades longitudinales de conexión local y nacional.
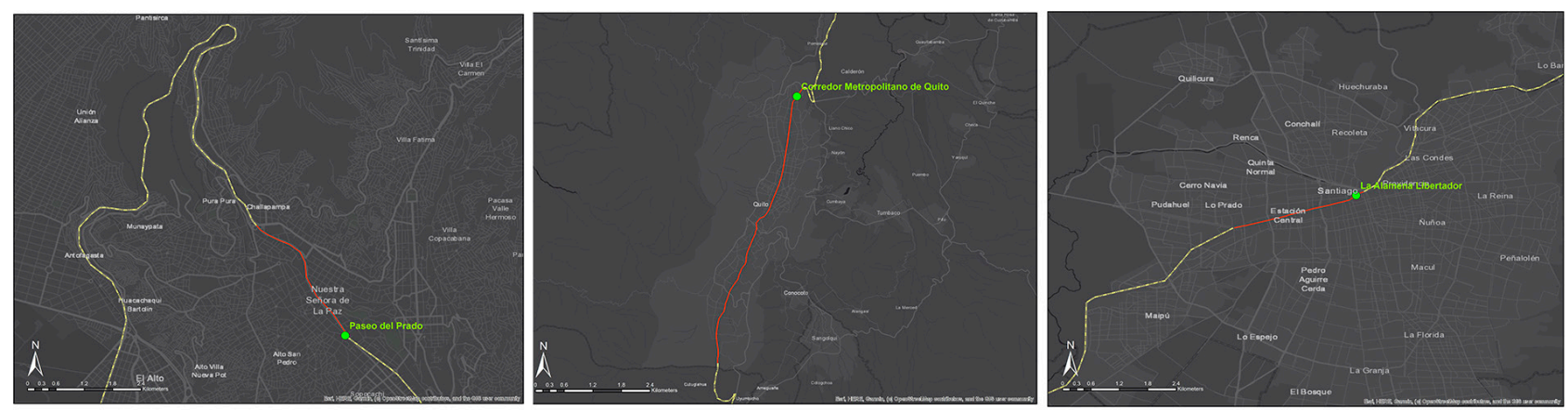

Fuente: Elaboración propia. 


\section{*.*vis revistainvi}

\section{Algunas reflexiones generales}

Los corredores urbanos conforman un recorrido con nodos urbanos, independientemente de: las diferencias de extensión (Guayaquil-10 de agosto -43 km- y Carrera Séptima -24 km-, o Avenida Paulista -3 km- y Libertador $-6 \mathrm{~km}$ ); de si se encuentran bajo superficie, como Paseo de la República, o sobre superficie, como Corrientes (8,6 km); de que sean muy anchos, como Paseo de la Reforma, o angostas, como Paseo del Prado; o de que sean financieros, como Avenida Paulista, o monumentales, como Paseo de la Reforma.

Las centralidades longitudinales tienen dos elementos comunes. Por un lado, son la columna vertebral de los sistemas de transportación de cada región urbana, gracias a la accesibilidad física y telemática, aunque también permiten la cualidad simultánea de centralidad longitudinal; por otro lado, detentan la condición de espacio público, generando ensambles multiescalares de la estructura urbana, de la región urbana y del sistema transurbano global.

Esto conduce a la relevancia de dos formas de centralidad urbana: la clásica, compuesta por un plano de puntos (Centro fundacional, Central Business District), y la nueva (corredor urbano), configurada a partir de una línea integrada por múltiples nodos secuenciales. Esta longitudinalidad es una nueva forma que adopta la modalidad de nodo para integrar la región urbana con el sistema transurbano global, de modo que "el norte de las ciudades del sur se articula con las ciudades del norte" (Sassen, 2003).

De la existencia de la pluralidad de centralidades urbanas (por tipo y numero) dentro de una ciudad se desprende la necesidad de construir políticas urbanas para: i) regular los mercados inmobiliarios en un momento en que la financiarización entra con fuerza (funciones centrales); ii) invertir en infraestructuras de base; y iii) constituir sistemas de centralidades donde el espacio público recupere su condición estructuradora de ciudad, y no el privado. Todo esto supone pasar del urbanismo de proyectos al urbanismo ciudadano, donde la escala sea humana y el sentido de la vida urbana sea la calidad y no la ganancia.

Los corredores urbanos, desde los inicios de las ciudades, son una parte tan fundamental de la planificación y construcción de las urbes que han estructurado la forma de cada una de ellas. Cabe destacar que son conectores o articuladores importantes que tienen elementos comunes y distintos, como se puede verificar a partir de las tipologías analíticas de historicidad (antigüedad, modernidad), funcionalidad central (económica, gubernamental) y accesibilidad (absoluta, relativa) y localización (borde, céntrica).

De esta manera, se ha instalado un debate en torno a tomar en cuenta a todas las centralidades como históricas y ya no solo a las que cuentan con mayor noción de antigüedad (fundacionales), pues las posteriores (Central Business District) y las más recientes centralidades longitudinales (corredores urbanos) son producidas y ocurren en momentos históricamente determinados. Y, por otro lado, el conjunto de centralidades debería actuar como un sistema, pero la lógica neoliberal de la ciudad lo impide; lleva a que las centralidades compitan entre sí, a que algunas de ellas pierdan su valor e incluso, en otros casos, a que su condición de espacio público sea de beneficio privado (Ramírez, 2021). 


\section{粼 revistainvi}

Por lo tanto, los corredores urbanos se transforman de simples vías en centralidades longitudinales de alcance nacional, regional y global, directamente relacionadas al desarrollo de la ciudad. Así, además, se abre el camino a entender cómo estos corredores empiezan una nueva etapa de posible decadencia a partir de la generalización de la era digital que traslada la base material de las ciudades a las plataformas virtuales. El auge del trabajo remoto disminuye la cantidad de población, genera el cierre de oficinas físicas y los grandes complejos corporativos se trasladan al mundo virtual, lo que evidentemente transforma los territorios y las centralidades. 


\section{Referencias bibliográficas}

Alcocer, J. (2000). El paseo de la reforma de la ciudad de México. De su trazado originario y paseo decimonónico a su condición actual de área de centralidad. (Tesis de Doctorado, Universidad de Valladolid, España). https://dialnet.unirioja.es/servlet/tesis?codigo=159653

Aristóteles. (2015). Política (G. Livov, trad.). Prometeo.

Bourdieu, P. (1999). Efectos de lugar. En P. Bourdieu, La miseria del mundo (pp. 119-124). Ákal.

Carmona, L. (2002). Montevideo: proceso planificador y crecimientos. Udelar.

Carrión, F. (2012). El desafío político de gobernar una ciudad-región. Cuestiones Urbano Regionales Revista del Instituto de la Ciudad, 1(1), 127-137.

Carrión, F. (2021). La ciudad neoliberal en América Latina. En P. Ramírez (Coord.), Espacios públicos y ciudadanías en conflicto en la Ciudad de México (pp. 11-40). UNAM, Instituto de Investigaciones Sociales.

Carrión, F. y Cepeda, P. (2020). Ciudades de plataforma: la Uberización. Foro Nacional por Colombia, (101-102), 80-91.

Casas Matiz, E. I. (2013). Impacto socio espacial de la peatonalización de la carrera séptima. Revista De Investigación, 6(2), 227-236. https://doi. org/10.29097/2011-639X.156

Castells, M. (1974). La cuestión urbana. Marsilio Editori.

Castells, M. (1997). ¿Fin del Estado nación? https://red.pucp. edu.pe/ridei/wp-content/uploads/biblioteca/Manuel $\% 20$ Castells $\% 20$ Fin.pdf

Chini, V. S. F. (2019). Eixão do lazer de Brasília: o Eixo Rodoviário Residencial e seu uso como espaço público. (Tesis de Maestría, Universidade de Brasilia). https://repositorio.unb.br/handle/10482/36963
Cuadrado-Roura, J. y Fernández, J. (2005). Las áreas metropolitanas frente al desafío de la competitividad. En E. Rojas, J. R. Cuadrado-Roura y J. M. Fernández Güell (Eds.), Gobernar las metrópolis (63-110). Banco Interamericano de Desarrollo.

Garza, G., Sobrino, J. A., y Jiménez, C. (2013). Teoría de las condiciones y los servicios generales de la producción. Colmex.

Gruschetsky, V. (2009). Congestión y descongestión en el centro de la ciudad: una razón para ensanchar la calle Corrientes. Buenos Aires 1927-1932. Serie Urbana, 9, 47-59.

Guevara, J. (2007). Metodología de investigación para la caracterización de corredores urbanos. Psicología para América Latina, (10).

Harvey, D. (2005). Produção capitalista do espaço. Annablume.

Hidalgo, G. (2015). Calles que fueron caminos: Intensificación de la trama de calles al sur de la Alameda en Santiago de Chile hasta fines del siglo XIX. Historia (Santiago), 48(1), 195-244. https://doi.org/10.4067/ $\underline{\text { S0717-71942015000100006 }}$

Hoyos, G. (2009). El cambio urbano. Concentración, difusión descentrada y desarticulación. Quivera, 11(1), 103-124.

Major agglomerations of the world. (2021). City population. https://www.citypopulation.de/en/world/agglomerations/

Marechal, L. (2013). Historia de la calle Corrientes. Dunken.

Márquez-López, L. (2016). Acumulación del capital inmobiliario y apropiación social del espacio público en el Paseo de la Reforma, Ciudad de México. Economía, sociedad y territorio, 16(50), 71-101. https://doi. org/10.22136/est0502016760 
Martínez, J. A. (2000). El Paseo de la Reforma de la ciudad de México. De su trazado originario y paseo decimonónico a su condición actual de área de centralidad. (Tesis de Maestría, Universidad de Valladolid, España).

Oliveira, M. A. (1998). Avenida Paulista: a produção contemporânea de uma paisagem de poder. (Tesis de Magister, Universidad Estadual de Campinas, Brasil).

Panerai, P., y Mangin, D. (2002). Proyectar la ciudad. Celeste Ediciones.

Pradilla Cobos, E. (2004). Ciudad de México: los caminos de la privatización de lo urbano. Revista Ciudades, (64), 57-62.

Pradilla Cobos, E. (2010). Mundialización neoliberal, cambios urbanos y políticas estatales en América Latina. Cadernos Metrópole, 12(24), 507-533.

Priore Lima, R. (2014). La avenida cambiante: las transformaciones de la Avenida Paulista en São Paulo y la construcción de su centralidad lineal. En VI Seminario Internacional de Investigación en Urbanismo, Barcelona-Bogotá, junio 2014. Departament d'Urbanisme i Ordenació del Territori. Universitat Politécnica de Catalunya.

Ramírez, P. (2021). Espacios públicos y ciudadanías en conflicto en la Ciudad de México. UNAM, Instituto de Investigaciones Sociales.

Rojas, E., Cuadrado-Roura, J., y Fernández, J. M. (2005). Gobernar las metrópolis. BID.

Santos, W. y Proença, A. (2020). A infraestrutura rodoviária e a urbanização regional contemporânea no território paulista: o caso do corredor urbano Campinas-Sorocaba. Eure, 46(138), 235-256. https://doi. org/10.4067/S0250-71612020000200235

Sassen, S. (1995). On concentration and centrality in the global city. En R. Robertson y K. White, Globalization. Critical concepts in sociology (pp. 63-78). Taylor $\&$ Francis.
Sassen, S. (2003). Localizando ciudades en circuitos globales. Eure, 29(88), 5-27. https://doi.org/10.4067/ S0250-71612003008800001

Secchi, B. (2001). La práctica actual de la proyección territorial. En X. Eizaguirre, La construcción del territorio disperso. Universidad Politécnica de Cataluña.

Singer, P. (1976). Urbanización, dependencia y marginalidad en América Latina. ILPES CEPAL.

Soja, E. (2005). Algunas consideraciones sobre el concepto de ciudades región globales. Ekonomiaz: Revista vasca de economía, (58), 44-75.

The world according to GaWC. (2020). Geography Department at Loughborough University. https://www. lboro.ac.uk/gawc/world2020t.html 


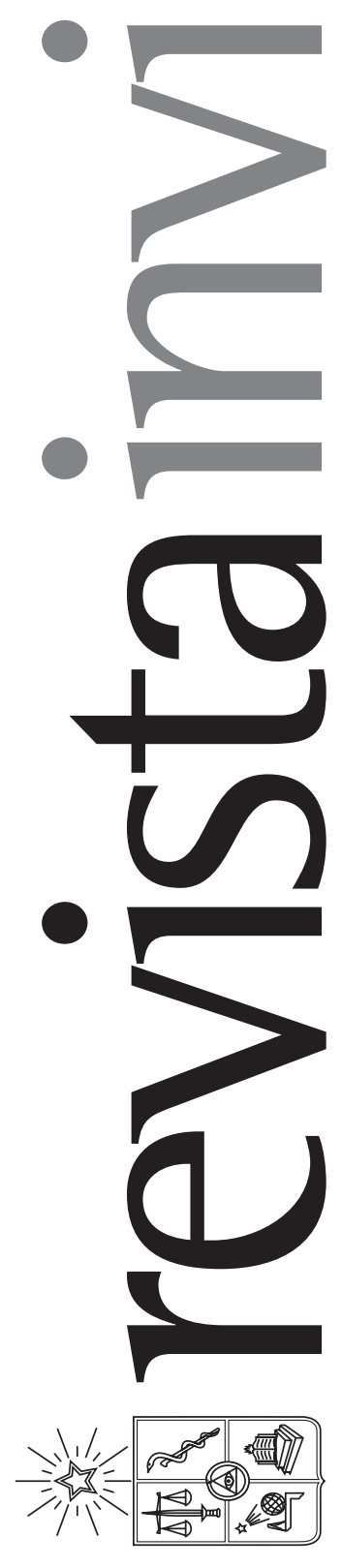

Revista INVI es una publicación periódica, editada por el Instituto de la Vivienda de la Facultad de Arquitectura y Urbanismo de la Universidad de Chile, creada en 1986 con el nombre de Boletín INVI. Es una revista académica con cobertura internacional que difunde los avances en el conocimiento sobre la vivienda, el hábitat residencial, los modos de vida y los estudios territoriales. Revista INVI publica contribuciones originales en español, inglés y portugués, privilegiando aquellas que proponen enfoques inter y multidisciplinares y que son resultado de investigaciones con financiamiento y patrocinio institucional. Se busca, con ello, contribuir al desarrollo del conocimiento científico sobre la vivienda, el hábitat y el territorio y aportar al debate público con publicaciones del más alto nivel académico.

Directora: Dra. Mariela Gaete Reyes, Universidad de Chile, Chile Editor: Dr. Luis Campos Medina, Universidad de Chile, Chile

Editores asociados: Dr. Gabriel Felmer, Universidad de Chile, Chile.

\section{Dr. Pablo Navarrete, Universidad de Chile, Chile.}

Dr. Juan Pablo Urrutia, Universidad de Chile, Chile

Coordinadora editorial: Sandra Rivera, Universidad de Chile, Chile.

Asistente editorial: Katia Venegas, Universidad de Chile, Chile.

\section{COMITÉ EDITORIAL:}

Dr. Victor Delgadillo, Universidad Autónoma de la Ciudad de México, México.

Dra. María Mercedes Di Virgilio, CONICET/ IIGG, Universidad de Buenos Aires, Argentina. Dra. Irene Molina, Uppsala Universitet, Suecia.

Dr. Gonzalo Lautaro Ojeda Ledesma, Universidad de Valparaíso, Chile.

Dra. Suzana Pasternak, Universidade de São Paulo, Brasil.

Dr. Javier Ruiz Sánchez, Universidad Politécnica de Madrid, España.

Dra. Elke Schlack Fuhrmann, Pontificia Universidad Católica de Chile, Chile.

Dr. Carlos Alberto Torres Tovar, Universidad Nacional de Colombia, Colombia.

Sitio web: http://www.revistainvi.uchile.cl/

Correo electrónico: revistainvi@uchilefau.cl

Licencia de este artículo: Creative Commons Atribución-Compartirlgual 4.0

Internacional (CC BY-SA 4.0) 